\title{
Metabolic complications in acromegaly after neurosurgery: a meta-analysis
}

\author{
Alessia Cozzolino@1,*, Tiziana Feola@1,2,*, llaria Simonelli@33, Giulia Puliani®1, Valeria Hasenmajer@1,

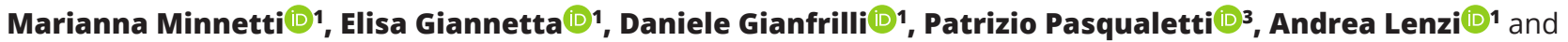 \\ Andrea M Isidori ${ }^{1}$ 1
}

${ }^{1}$ Department of Experimental Medicine, Sapienza University of Rome, Rome, Italy, ${ }^{2}$ Neuroendocrinology, Neuromed Institute, IRCCS, Pozzilli, Italy, and ${ }^{3}$ Medical Statistics and Information Technology, AFaR, Fatebenefratelli Hospital, Isola Tiberina, Rome, Italy

*(A Cozzolino and T Feola contributed equally to this work)

Correspondence

should be addressed

to A M Isidori

Email

andrea.isidori@uniroma1.it

\begin{abstract}
Objective: Neurosurgery is the first-line treatment for acromegaly. Whether metabolic disorders are reversible after neurosurgery is still debated. The meta-analysis aimed to address the following questions: (i) Does neurosurgery affect glycolipid metabolism? (ii) Are these effects related to disease control or follow-up length?

Design: A meta-analysis and systematic review of the literature.

Methods: Three reviewers searched databases until August 2019 for prospective trials reporting glycometabolic outcomes after neurosurgery. Three other extracted outcomes, all assessed the risk of bias.

Results: Twenty studies were included. Neurosurgery significantly reduced fasting plasma glucose (FPG) (effect size (ES): $-0.57 \mathrm{mmol} / \mathrm{L}, 95 \% \mathrm{Cl}:-0.82$ to $-0.31 ; P<0.001)$, glucose load (ES: $-1.10 \mathrm{mmol} / \mathrm{L}, 95 \% \mathrm{Cl}:-1.66$ to $-0.53 ; P<0.001)$, glycosylated haemoglobin (HbA1c) (ES: $-0.28 \%, 95 \% \mathrm{Cl}:-0.42$ to $-0.14 ; P<0.001$ ), fasting plasma insulin (FPI) (ES: $-10.53 \mathrm{mU} / \mathrm{L}, 95 \% \mathrm{Cl}:-14.54$ to $-6.51 ; P<0.001$ ), homeostatic model assessment of insulin resistance (HOMA-IR) (ES: $-1.98,95 \% \mathrm{Cl}:-3.24$ to $-0.72 ; P=0.002$ ), triglycerides (TGDs) (ES: $-0.28 \mathrm{mmol} / \mathrm{L}, 95 \% \mathrm{Cl}:-0.36$ to $-0.20 ; P<0.001$ ) and LDL-cholesterol (LDLC) (ES: $-0.23 \mathrm{mmol} / \mathrm{L}, 95 \% \mathrm{Cl}:-0.45$ to $-0.02 \mathrm{mmol} / \mathrm{L}) ; P=0.030$ ) and increased HDL-cholesterol (HDLC) (ES: $0.21 \mathrm{mmol} / \mathrm{L}, 95 \% \mathrm{Cl}: 0.14$ to $0.28 ; P<0.001$ ). Meta-regression analysis showed that follow-up length - not disease control - had a significant effect on FPG, with the greatest reduction in the shortest follow-up (beta $=0.012$, S.E. $=0.003 ; P=0.001$.

Conclusions: Neurosurgery improves metabolism with a significant decrease in FPG, glucose load, HbA1C, FPI, HOMA-IR, TGDs, and LDLC and increase in HDLC. The effect on FPG seems to be more related to follow-up length than to disease control.
\end{abstract}

\section{Introduction}

Acromegaly is associated with several comorbidities, predominantly comprising cardiovascular, respiratory and metabolic diseases $(1,2,3,4)$. Growth hormone (GH)-induced insulin resistance is considered the main mechanism for the increased prevalence of metabolic syndrome in acromegaly, although impaired pancreatic $\beta$-cell function and insulin secretion have also been proposed $(4,5,6)$. Most recent studies showed that insulin secretion is at least as important as insulin resistance in glucose metabolism abnormalities, suggesting that its impairment drives glucose intolerance $(7,8)$. GH hypersecretion also impairs insulin sensitivity, as its lipolytic effect causes an excessive free fatty acid release and adipokine imbalance, facilitating local and systemic

Published by Bioscientifica Ltd 
inflammation (9). Lipid disorders, such as reduced HDLcholesterol (HDLC) and hypertriglyceridemia, frequently accompany glucose imbalances $(1,3,4)$.

According to the latest guidelines and consensus statements $(10,11,12)$, transsphenoidal neurosurgery is the first-line treatment for intrasellar microadenomas, non-invasive macroadenomas and adenomas causing compressive symptoms. To date, no meta-analysis has evaluated the effects of neurosurgery on metabolism. Some studies highlighted that neurosurgery can improve glucose homeostasis and insulin sensitivity $(5,13)$, but others found that once $\beta$-cell function is impaired, abnormal glucose metabolism can persist even after successful neurosurgery $(5,13,14)$. Lipid disorders also persist in a significant percentage of acromegaly patients, despite disease control (4). Therefore, it is still unclear if neurosurgery is a viable option to target the metabolic complications of acromegaly, especially if it could not be curative.

The present meta-analysis aimed to answer this question by addressing the following issues: (i) Does neurosurgery affect FPG, HbA1c, glucose load (2-h oral glucose tolerance test 'OGTT'), FPI, HOMA-IR, TGDs, total cholesterol (TotalC), HDLC, LDL-cholesterol (LDLC), weight, BMI or waist circumference (WC)? (ii) Are these effects related to disease control or length of follow-up?

\section{Methods}

We performed the meta-analysis and systematic review following a rigorous protocol based on the Cochrane collaboration and PRISMA statements $(15,16)$. The study was prospectively registered with PROSPERO (CRD42019127379).

\section{Search strategy}

A comprehensive search of English language articles published from 1990 to 2019 was conducted in several databases (MEDLINE, EMBASE, Cochrane library and SCOPUS). The keywords were acromegaly AND diabetes, acromegaly AND glucose intolerance/hyperglycaemia/glucose, acromegaly AND neurosurgery, acromegaly treatment. A final update of the search was conducted in August 2019.

\section{Study selection}

We selected all studies that met the following eligibility criteria: (i) randomized controlled trials (RCTs) and cohort

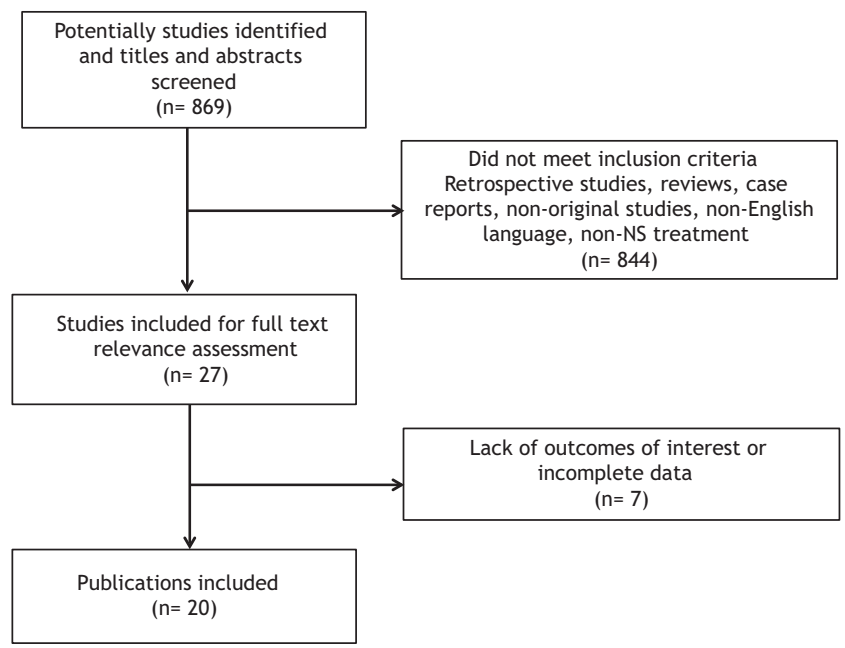

Figure 1

Flow-chart of the literature eligibility assessment process.

study without comparison; (ii) neurosurgery treatment in acromegaly patients; (iii) assessment of metabolic parameters before and after neurosurgery. Retrospective studies, reviews, case reports, animal studies and nonoriginal articles were excluded.

Three reviewers (AC, TF, and GP) independently screened all identified titles and abstracts and evaluated potentially eligible publications. There was a high level of inter-observer agreement (91\%). Any disagreement was resolved through open discussion. Figure 1 shows the study selection process.

\section{Data extraction and risk of bias analysis}

Three reviewers (AC, TF and VH) independently extracted the following data: study design; age; sex; previous medical treatments; mean neurosurgery follow-up and disease control (GH and IGF1 levels) before and after therapy; and percentage of remission, using the criteria reported in the various studies: post-OGTT GH: $<1 \mathrm{ng} / \mathrm{ml}$ (in one study, $<1.67 \mathrm{ng} / \mathrm{mL}$ (17) and in another, $<1.3 \mathrm{ng} /$ $\mathrm{mL}$ (6)); random $\mathrm{GH}<2.5 \mathrm{ng} / \mathrm{ml}$ (in one study, $\mathrm{GH}<4 \mathrm{ng} /$ $\mathrm{mL}$ (18)); normal IGF1 levels adjusted for age and sex; or post-OGGT GH $<1 \mathrm{ng} / \mathrm{mL}$ with normal IGF1 levels.

The risk of bias analysis on extracted data was performed by another investigator (MM) and all reviewers involved in study selection and extraction independently assessed the risk of bias according to the Cochrane risk-of-bias algorithm modified for cohort study without comparison by removing inapplicable criteria (19). 


\section{Outcomes}

Outcomes of interest included changes in FPG, HbA1c, glucose load, FPI, HOMA-IR, TGDs, TotalC, HDLC, LDLC, weight, BMI, and WC. Data on the glycaemic status, diabetes therapies and pituitary function of the patients were extracted. Studies with overlapping populations were excluded and only those with the most complete and recent data were selected.

\section{Data synthesis and statistical analysis}

\section{Data extraction and manipulation}

We extracted mean \pm S.D. or median and range at baseline and post-treatment or difference from baseline and/or percentage of change for all the above outcomes. When S.E. was reported, we calculated the corresponding s.D. and if necessary, we converted units of measurements in line with the International System of Units. We contacted the authors to obtain any missing data, but no further data were obtained. When median and range (or interquartile range) were reported, mean and S.D. were estimated (20).

\section{Meta-analysis}

We computed the mean difference (MD) between post- and pre-values; negative values indicate prevalues higher than post-values. The s.e. of the MD was calculated considering the correlation between the prepost measures. We performed the meta-analysis using a random-effects model for combining data into a pooled MD. We evaluated heterogeneity using the Chi-squared test, quantifying inconsistency by $\mathrm{I}^{2}$, according to Higgins et al. (21): $\mathrm{I}^{2} 0 \%=$ no heterogeneity; $\mathrm{I}^{2} 25 \%=$ low heterogeneity; $\mathrm{I}^{2} 50 \%=$ moderate heterogeneity and $\mathrm{I}^{2}$ $75 \%=$ high heterogeneity. To investigate the possible sources of heterogeneity, the effect of the post-pre MD in GH and IGF1 values and the effect of length of follow-up were evaluated by meta-regression analysis, when close to ten studies reported the outcome of interest. Subgroup analyses were also performed. To explore if the duration of follow-up influences the effects of neurosurgery on metabolism outcomes, the studies were stratified by the mean follow-up ( $<6$ months; $\geq 6$ months). They were then categorized by the percentage of patients with safe $\mathrm{GH}$, according to the criteria used in the studies, normal IGF1 for sex and age, or both, arbitrarily divided into two groups ( $<80 \%$ or $\geq 80 \%$ patients at target) to establish if the effect of neurosurgery on metabolism correlates with disease control. They were also stratified by previous treatment with somatostatin analogs (SSAs) and by study quality. Publication bias was investigated by funnel plot, the interpretation of which was aided by contourenhanced funnel plot, which also includes contours of statistical significance. Egger's test was then used to provide statistical evidence for funnel plot symmetry. The estimated effect size (ES) was reported as MD and 95\% CI. $P<0.05$ was considered statistically significant. All the statistical analyses were performed with STATA 10.1.

\section{Results}

\section{Study selection}

Figure 1 shows the study eligibility assessment process.

\section{Study characteristics}

Table 1 summarizes the details of the 20 selected studies, of which two included two different study populations (22, 23). Data were available from 397 intention-to-treat (ITT) subjects, $189 \mathrm{M}$ and $193 \mathrm{~F}$ (one study did not specify sex (24)), with a mean age of 47.7 years (range $28-76$ years). Study characteristics varied in length of follow-up, from 1 week to 5 years. Only two study populations had received previous SSA treatment $(22,23)$. Only seven studies (18, $25,26,27,28,29,30)$ reported data on pre-neurosurgery pituitary hormone deficiency and only eight $(18,25$, $27,28,29,30,31,32$ ) on post-neurosurgery pituitary hormone deficiency, with most finding no pre- or postneurosurgery deficiency. Only three studies described hormone deficiency before $(26,29,30)$ and three studies after neurosurgery $(29,30,31)$.

\section{Glycometabolic outcomes}

Thirteen studies (including 15 study populations) investigated the effect of neurosurgery on FPG (265 patients); overall, there was a significant decrease in blood glucose (ES: $-0.57 \mathrm{mmol} / \mathrm{L}$ (95\% CI: -0.82 to $-0.31 \mathrm{mmol} / \mathrm{L}) ; P<0.001)$, but with high heterogeneity $\left(\mathrm{I}^{2}=76.4 \% ; P<0.001\right)(17,18,22,23,24,25,27,28,30$, $32,33,34,35$ ) (Fig. 2). The data were confirmed by the concomitant decrease in HbA1c, as evaluated in four study populations (85 patients) (ES: $-0.28 \%$ (95\% CI: -0.42 to $-00.14 \%) ; P<0.001)(23,32,33)$, but again, with high heterogeneity $\left(\mathrm{I}^{2}=86.8 \% ; P<0.001\right)$.

Three study populations (69 patients) evaluated glucose load; overall, there was a significant decrease (ES: -1.10 
Table 1 Details of selected studies. The percentage of disease control is expressed using the following criteria: normal IGF1 levels adjusted to age and gender and GH is specified in brackets for each study.

\begin{tabular}{|c|c|c|c|c|c|c|c|}
\hline Reference & $\begin{array}{c}\text { No. of } \\
\text { patients }(M / F)\end{array}$ & $\begin{array}{c}\text { Age (years) } \\
\text { (mean } \pm \text { S.D. or } \\
\text { range) }\end{array}$ & $\begin{array}{l}\text { Mean follow-up } \\
\text { (months) }\end{array}$ & $\begin{array}{l}\text { Previous } \\
\text { medical } \\
\text { therapy }\end{array}$ & Disease control (\%) & $\begin{array}{l}\text { Pituitary } \\
\text { hormones } \\
\text { deficiency pre-NS }\end{array}$ & $\begin{array}{l}\text { Pituitary } \\
\text { hormones } \\
\text { deficiency } \\
\text { post-NS }\end{array}$ \\
\hline (18) & $6(2 / 4)$ & $41.2 \pm 25.2$ & 2 & No & $100(\mathrm{GH}<4)$ & No & No \\
\hline (17) & $9(4 / 5)$ & $54(44-75)$ & 12 & No & $100(\mathrm{GH}<1.67)$ & NA & NA \\
\hline (31) & $14(8 / 6)$ & $49.4 \pm 13.8$ & 11.5 & No & $100(\mathrm{GH}<1)$ & NA & Yes (7.1\% HT) \\
\hline (32) & $6(4 / 2)$ & $52 \pm 8.4$ & $3-4$ & No & $16.7(\mathrm{GH})$ & NA & No \\
\hline (25) & $20(6 / 14)$ & $48.4 \pm 10.4$ & 2 & No & $\begin{array}{c}85 \text { (OGTT GH }<1) \\
100 \text { (IGF-1); } 85 \\
(\text { GH+IGF1) }\end{array}$ & No & No \\
\hline (6) & $11(6 / 5)$ & $55.4 \pm 10.8$ & $0.25-0.5$ & No & $\begin{array}{l}100 \text { (OGTT GH } \\
<1.3) ; 100 \text { (IGF1) }\end{array}$ & NA & NA \\
\hline (38) & $6(3 / 3)$ & NA & 6 & No & $100($ IGF1) & NA & NA \\
\hline (26) & $9(4 / 5)$ & $43.4 \pm 12.3$ & 10 & No & $100($ IGF1) & Yes (22.2\% HT) & NA \\
\hline (36) & $31(16 / 15)$ & $48.1 \pm 11.2$ & 6 & No & $\begin{array}{c}100 \text { (OGTT GH }< \\
1+\text { IGF1) }\end{array}$ & NA & NA \\
\hline (35) & $16(8 / 8)$ & $48 \pm 16$ & 4 & No & $\begin{array}{l}63 \text { (OGTT } \\
\quad \mathrm{GH}<1+\mid \mathrm{GF} 1)\end{array}$ & NA & NA \\
\hline (27) & $5(2 / 3)$ & $56 \pm 3.2$ & 3 & No & NA & No & No \\
\hline (33) & $17(8 / 9)$ & $48 \pm 3.2$ & 3 & No & 82.3 (OGTT GH < 1) & NA & NA \\
\hline (22) & $30(13 / 17)$ & $54 \pm 14$ & 60 & No & NA & NA & NA \\
\hline (22) & $20(11 / 9)$ & $45 \pm 15$ & 60 & Yes & NA & NA & NA \\
\hline (37) & $19(8 / 11)$ & $42.7 \pm 10.3$ & 55.2 & No & $100(\mathrm{GH}<1+$ /or IGF1) & NA & NA \\
\hline (34) & $24(15 / 9)$ & $28-76$ & $2.9^{*}$ & No & NA & NA & NA \\
\hline (28) & $20(10 / 10)$ & $51 *(21-70)$ & $0.3^{*}$ & No & $45(\mathrm{GH}<1) ; 35(\mathrm{IGF1})$ & No & No \\
\hline (29) & $42(24 / 18)$ & $44.5 \pm 1.7$ & 5.7 & No & 61.9 (IGF1) & $\begin{array}{c}\text { Yes ( } 4.8 \% \mathrm{HC} \text {; } \\
2.4 \% \mathrm{HT} ; \\
62.5 \% \text { male } \\
\text { HG; } 22.2 \% \\
\text { female HG) }\end{array}$ & $\begin{array}{l}\text { Yes (0\% HC; } 2.4 \% \\
\text { HT; } 20.8 \% \\
\text { male HG; } 5.5 \% \\
\text { female HG) }\end{array}$ \\
\hline (24) & 7 & NA & 6 & No & $100(\mathrm{OGTT}$ GH < 1) & NA & NA \\
\hline (30) & $23(10 / 13)$ & $43.5 \pm 12.5$ & 12 & No & 82.6 (IGF1) & $\begin{array}{c}\text { Yes }(8.7 \% \mathrm{HC} ; \\
8.7 \% \mathrm{HT} ; \\
17.4 \% \mathrm{HG})\end{array}$ & $\begin{array}{l}\text { Yes ( } 4.3 \% \mathrm{HC} ; \\
\text { 4.3\% HT; } 1 \% \\
\text { male HG) }\end{array}$ \\
\hline (23) & $30(11 / 18)$ & $45 \pm 12$ & 3 & No & NA & NA & NA \\
\hline (23) & $32(16 / 9)$ & $47 \pm 14$ & 3 & Yes & NA & NA & NA \\
\hline
\end{tabular}

The percentage of disease control is expressed using the following criteria: normal IGF1 levels adjusted to age and gender and GH is specified in brackets for each study.

*Median.

$H C$, hypocortisolism; $H G$, hypogonadism; $H T$, hypothyroidism.

$\mathrm{mmol} / \mathrm{L}(95 \%$ CI: -1.66 to $-0.53 \mathrm{mmol} / \mathrm{L}) ; P<0.001)$, with very high heterogeneity $\left(\mathrm{I}^{2}=90.6 \% ; P<0.001\right)(23,24)$. The meta-analysis also revealed a significant decrease in FPI levels in ten studies involving 140 patients (ES: -10.53 $\mathrm{mU} / \mathrm{L}$ (95\% CI: -14.54 to $-6.51 \mathrm{mU} / \mathrm{L}) ; P<0.001$ ), but with an extremely high heterogeneity $\left(\mathrm{I}^{2}=96.3 \% ; P<0.001\right)$ $(17,18,25,26,27,28,31,33,34,35)$. Neurosurgery also significantly reduced HOMA-IR (nine studies, 189 patients) (ES: -1.98 (95\% CI: -3.24 to -0.72$) ; P=0.002$ ), but again, with an extremely high heterogeneity $\left(\mathrm{I}^{2}=99.4 \%\right.$; $P<0.001)(6,27,28,29,30,33,34,35,36)$ (Fig. 3).

In relation to lipid metabolism, seven studies (134 patients) evaluated the effect of neurosurgery on TGDs, revealing a significant drop after treatment (ES: -0.28 $\mathrm{mmol} / \mathrm{L}$ (95\% CI: -0.36 to $-0.20 \mathrm{mmol} / \mathrm{L}) ; P<0.001$ ), with moderate heterogeneity $\left(\mathrm{I}^{2}=60.9 \% ; P=0.018\right)(18$, 25, 29, 31, 33, 35, 37) (Fig. 4).

Conversely, no change was found in total-C (five studies, 112 patients; ES: $0.42 \mathrm{mmol} / \mathrm{L}$ (95\% CI: -1.04 to $1.89 \mathrm{mmol} / \mathrm{L}) ; P=0.572$ ), with an extremely high heterogeneity $\left(I^{2}=99.7 \% ; P<0.001\right)(25,29,31,33$, 37). HDLC significantly increased after neurosurgery in four studies (95 patients) (ES: $0.21 \mathrm{mmol} / \mathrm{L}$ (95\% CI: 0.13 to $0.28 \mathrm{mmol} / \mathrm{L}) ; P<0.001$ ), with extremely high heterogeneity $\left(\mathrm{I}^{2}=98.8 \% ; P<0.001\right)(25,29,33$, 35). Three of these studies (79 patients) also found a 


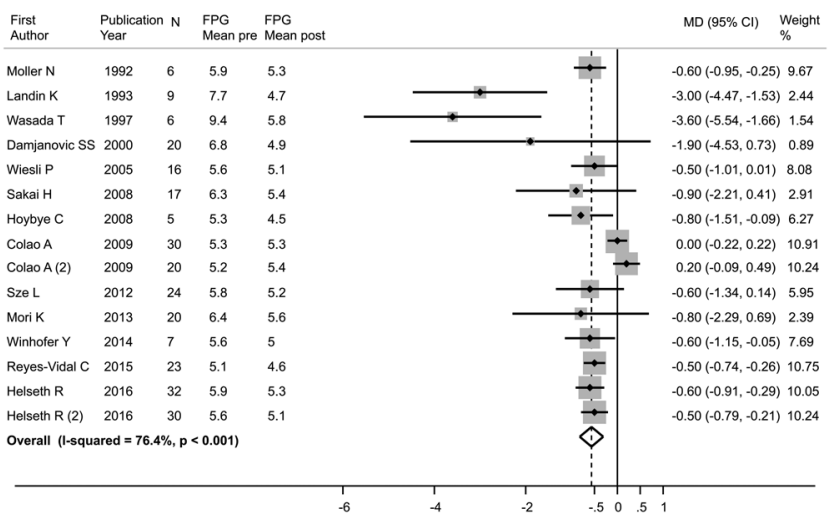

\section{Figure 2}

Results of the main analysis of neurosurgery effects on FPG in acromegaly. Single studies are identified by the first author and publication year. Weights are from random-effects analysis. The number ' 2 ' in parentheses refers to studies in which two groups of patients were analysed separately.

significant decrease in LDLC (ES :-0.23 mmol/L (95\% CI: -0.45 to $-0.02 \mathrm{mmol} / \mathrm{L}) ; P=0.030)$, with an extremely high heterogeneity $\left(\mathrm{I}^{2}=98.9 \% ; P<0.001\right)(25,29,33)$. No significant change was found in BMI (seven studies; 125 patients; ES: $0.06 \mathrm{~kg} / \mathrm{m}^{2}$ (95\% CI: -0.46 to $0.57 \mathrm{~kg} / \mathrm{m}^{2}$ ); $P=0.833, \mathrm{I}^{2}=63.8 \%$; and $\left.P=0.011\right)(17,25,30,33,36,37$, $38)$, in weight (five studies; 96 patients; ES: $1.19 \mathrm{~kg}(95 \%$ CI: -0.30 to $2.68 \mathrm{~kg}) ; P=0.116, \mathrm{I}^{2}=86.0 \%$; and $P<0.001$ ) $(17,29,30,35,38)$, or in WC (three studies; 81 patients; ES $2.06 \mathrm{~cm}$ (95\% CI: -0.20 to $4.32 \mathrm{~cm}) ; P=0.074, \mathrm{I}^{2}=87.5 \%$; and $P<0.001)(29,30,35)$.

Only about half of the studies reported both pre- and post-treatment data on glycaemic status and diabetes treatments and only one study provided data according

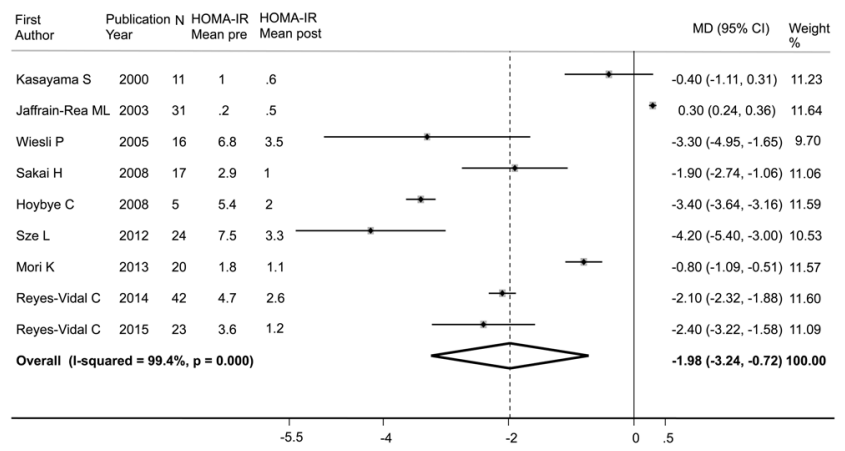

\section{Figure 3}

Results of the main analysis of neurosurgery effects on HOMA-IR in acromegaly. Single studies are identified by the first author and publication year. Weights are from randomeffects analysis.

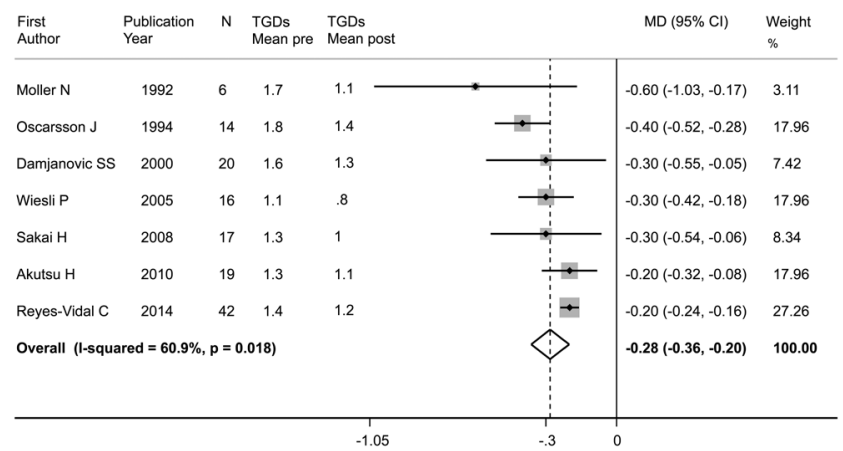

Figure 4

Results of the main analysis of neurosurgery effects on TGDs in acromegaly. Single studies are identified by the first author and publication year. Weights are from random-effects analysis.

to baseline glycaemic status (6). It was therefore not possible to adjust for this confounding factor. Overall, 15 studies provided the number of patients with diabetes at baseline $(42 / 282,14.9 \%)(17,18,22,24,26,27,28$, $29,30,31,32,33,34,36,37)$ and 12 of these provided the number of diabetic patients after treatment $(26 / 245$, $10.6 \%)(2,18,22,24,26,28,29,30,31,34,36,37)$. Five studies reported the diabetes therapies at baseline $(26,29$, $31,32,34)$ and four of these reported any change after neurosurgery $(29,31,32,34)$. Overall, nine of 18 diabetic patients (50\%) were taking oral hypoglycaemic agents and nine (50\%) were taking insulin therapy at baseline. After neurosurgery, four patients had reduced or stopped oral hypoglycaemic agents and seven had reduced or stopped insulin therapy.

The results for both the main and subgroup analyses are reported in Table 2 and Supplementary Table 1 (see section on supplementary materials given at the end of this article).

\section{Meta-regression}

Since the minimum number of studies required was set as ten, meta-regression analyses were possible only for FPG and FPI, but not other outcomes. Meta-regression analyses showed a significant effect of the length of follow-up on FPG (beta $=0.012$, s.E. $=0.003 ; P=0.001$ ), but not on FPI (beta $=-0.07$, s.e. $=0.356 ; P=0.844$ ). As shown in Fig. 5, the greatest reduction in FPG was seen for the shortest follow-up, whereas the reduction shrank, tending towards zero, as the length of follow-up increased. This trend seems to be based on the findings of the study published by Colao, including two populations (22). Removing this 
Table 2 Summary of results of meta-analysis on glucose and lipid metabolism outcomes: main analysis.

\begin{tabular}{|c|c|c|}
\hline Main analysis & No. of studies & No. of patients \\
\hline FPG (mmol/L) & 13 & 265 \\
\hline HbA1c (\%) & 3 & 85 \\
\hline $\begin{array}{l}\text { Glucose load } \\
\text { (mmol/L) }\end{array}$ & 2 & 69 \\
\hline FPI (mU/L) & 10 & 140 \\
\hline HOMA-IR & 9 & 189 \\
\hline TGDs (mmol/L) & 7 & 134 \\
\hline TotalC (mmol/L) & 5 & 112 \\
\hline HDLC (mmol/L) & 4 & 95 \\
\hline LDLC (mmol/L) & 3 & 79 \\
\hline $\mathrm{BMI}\left(\mathrm{kg} / \mathrm{m}^{2}\right)$ & 7 & 125 \\
\hline Weight (kg) & 5 & 96 \\
\hline$W C(\mathrm{~cm})$ & 3 & 81 \\
\hline
\end{tabular}

\begin{tabular}{l}
\hline Mean diff. $95 \% \mathbf{C l}$ \\
\hline$-0.57(-0.82$ to \\
$-0.31)$ \\
$-0.28(-0.42$ \\
to -0.14$)$ \\
$-1.10(-1.66$ to \\
$-0.53)$ \\
$-10.53(-14.54$ to \\
$-6.51)$ \\
$-1.98(-3.24$ to \\
$-0.72)$ \\
$-0.28(-0.36$ to \\
$-0.20)$ \\
$0.42(-1.04$ to 1.89$)$ \\
$0.21(0.14$ to -0.28$)$ \\
$-0.23(-0.45$ \\
to -0.02$)$ \\
$0.06(-0.46$ to 0.57$)$ \\
$1.19(-0.30$ to 2.68$)$ \\
$2.06(-0.20$ to 4.32$)$ \\
\hline
\end{tabular}

\begin{tabular}{|c|c|}
\hline$P$-value & I-squared (\%) \\
\hline$<0.001$ & 76.4 \\
\hline$<0.001$ & 86.8 \\
\hline$<0.001$ & 90.6 \\
\hline$<0.001$ & 96.3 \\
\hline 0.002 & 99.4 \\
\hline$<0.001$ & 60.9 \\
\hline 0.572 & 99.7 \\
\hline$<0.001$ & 98.8 \\
\hline 0.030 & 98.9 \\
\hline 0.833 & 63.8 \\
\hline 0.116 & 86.0 \\
\hline 0.074 & 87.5 \\
\hline
\end{tabular}

Ref.
$\begin{gathered}(17,18,22,23,24,25,27, \\ 28,30,32,33,34,35)\end{gathered}$

$(23,32,33)$

$(23,24)$

$(17,18,25,26,27,28,31$, $33,34,35)$

$(6,27,28,29,30,33,34$, $35,36)$

$(18,25,29,31,33,35,37)$

$(25,29,31,33,37)$

$(25,29,33,35)$

$(25,29,33)$

$(17,25,30,33,36,37,38)$

$(17,29,30,35,38)$ $(29,30,35)$

FPG, fasting plasma glucose; FPI, fasting plasma insulin; Glucose load, 2-h oral glucose tolerance test; HbA1c, glycosylated haemoglobin; HDLC, HDL cholesterol; HOMA-IR, homeostatic model assessment of insulin resistance; LDLC, LDL cholesterol; Ref., references; TGDs, triglycerides; TotalC, total cholesterol; WC, waist circumference.

study from the meta-regression analysis there was no effect of follow-up length on FPG (beta $=0.005$, s.e. $=0.022$; $P=0.835)$. Conversely, neither the IGF1 MD nor the GH MD affected FPG or FPI MD.

\section{Risk of bias}

As summarized in Table 3, most of the studies had a low risk of attrition and reporting bias. Only two studies had a high risk of attrition bias $(23,36)$ and seven of reporting

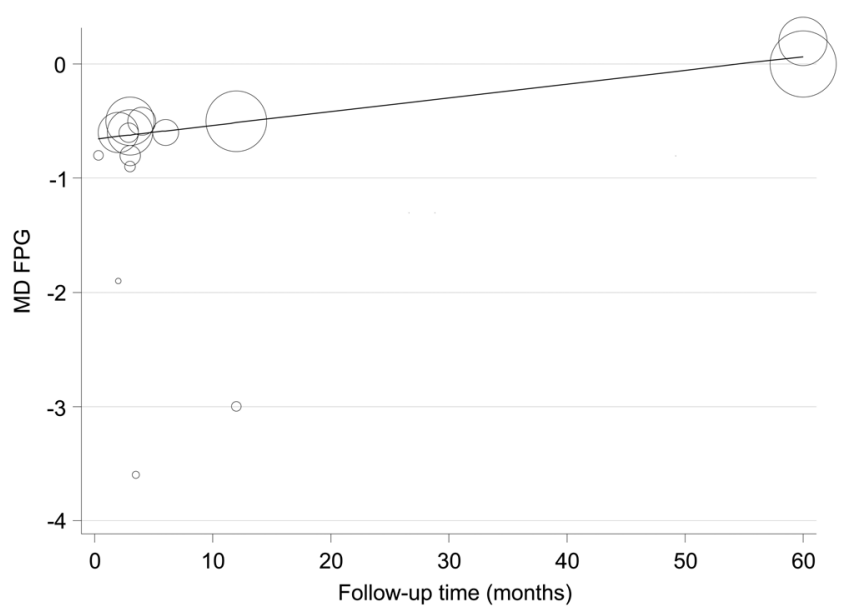

Figure 5

Meta-regression analysis showing the effect of the length of follow-up on FPG. bias $(6,22,24,29,30,34,37)$. The funnel plot showed a significant asymmetry for FPG $(b=-2.33, P=0.009)$, HbA1c $(b=-3.53, P=0.043)$ and BMI $(b=2.29, P=0.023)$.

\section{Discussion}

This meta-analysis reveals that neurosurgery has a good impact on glucose and lipid metabolism in acromegaly, inducing a statistically significant - albeit clinically mild - decrease in FPG, glucose load and HbA1c, and a more meaningful reduction of FPI and, consequently, of HOMA-IR. It also led to a slightly less atherogenic lipid profile, with a statistically significant decrease in TGDs and LDLC and an increase in HDLC. The improvement of metabolic comorbidities and arterial hypertension is one of the goals of acromegaly treatment to reduce the associated cardiovascular morbidity and mortality (39, 40). The long-term persistence of such comorbidities once successful treatment has been achieved is still under debate. The effect of the different medical therapies of acromegaly on metabolism was recently investigated in two meta-analyses: the first evaluated the effect of SSAs and the second the effect of PEG, in monotherapy and combination with SSAs $(41,42)$. SSAs were found to slightly impair glucose homeostasis while improving disease control (41). In contrast, PEG in monotherapy or combined with SSAs improved glucose metabolism, independently of disease control (42). 
Table 3 Risk of bias summary per Cochrane metrics.

\begin{tabular}{|c|c|c|c|c|c|c|}
\hline References & Selection bias & Performance bias & Detection bias & Attrition bias & Reporting bias & Other bias \\
\hline (18) & $\mathrm{NE}$ & NE & NE & - & - & - \\
\hline (17) & $\mathrm{NE}$ & NE & NE & - & - & - \\
\hline (31) & $\mathrm{NE}$ & $\mathrm{NE}$ & NE & - & - & - \\
\hline (32) & NE & NE & NE & - & - & - \\
\hline (25) & $\mathrm{NE}$ & NE & NE & - & - & - \\
\hline (6) & $\mathrm{NE}$ & NE & NE & - & + & - \\
\hline (38) & $\mathrm{NE}$ & NE & NE & - & - & - \\
\hline (26) & NE & NE & NE & - & - & - \\
\hline (36) & NE & NE & NE & + & $?$ & - \\
\hline (35) & $\mathrm{NE}$ & NE & NE & - & - & - \\
\hline (27) & $\mathrm{NE}$ & NE & NE & - & - & - \\
\hline (33) & $\mathrm{NE}$ & NE & NE & - & - & - \\
\hline (22) & NE & NE & NE & - & + & - \\
\hline (22) & $\mathrm{NE}$ & $\mathrm{NE}$ & NE & - & + & - \\
\hline (37) & $\mathrm{NE}$ & NE & NE & - & + & - \\
\hline (34) & $\mathrm{NE}$ & NE & NE & - & + & - \\
\hline (28) & $\mathrm{NE}$ & $\mathrm{NE}$ & $\mathrm{NE}$ & - & - & - \\
\hline (29) & NE & NE & NE & - & + & - \\
\hline (24) & $\mathrm{NE}$ & $\mathrm{NE}$ & $\mathrm{NE}$ & - & + & - \\
\hline (30) & NE & $\mathrm{NE}$ & NE & - & + & - \\
\hline (23) & $?$ & $?$ & $?$ & + & - & - \\
\hline (23) & $?$ & $?$ & $?$ & + & - & - \\
\hline
\end{tabular}

International guidelines and consensus statements on acromegaly treatment recognize neurosurgery as the first-line treatment $(10,11)$, but it is still unclear if metabolic complications are reversible after neurosurgery and if this depends on disease control. Neurosurgery has been shown to improve metabolism $(4,5,13,40)$. Jonas et al. found a decrease in FPG in patients cured by neurosurgery, whereas it increased in patients controlled with SSAs and in patients with active disease (43). A retrospective study evaluating the course of diabetes and hypertension after multimodal treatment of acromegaly showed that diabetes was less prevalent on the last visit in patients who achieved surgical remission than in those who persisted with active disease (40). However, metabolic disorders could persist even after the cure $(4,5,13,14)$. The prevalence of diabetes after remission seems to be higher than in the general population, suggesting that long-term monitoring of glucose parameters is required, even after disease remission (44). Kinoshita et al. proposed that impairment of $\beta$-cell function at diagnosis may be a possible explanation for the persistence of glycometabolic disorders even after successful neurosurgery (14).

Data from the French Acromegaly Registry show that GH and IGF1 levels did not appear as predictive factors for the presence of diabetes in acromegaly patients (45). In contrast, Alexopoulou et al. found that a family history of diabetes and IGF1 levels were associated with hyperglycaemia, whereas BMI and IGF1 levels were associated with insulin resistance (46). This discrepancy probably suggests that other modifying factors modulate the overall risk of diabetes in patients with acromegaly.

The results of subgroup analysis for the length of follow-up suggest that the decrease in FPG is dependent on the time elapsed since neurosurgery, retaining statistical significance only in the short term. Conversely, the change in FPI seems to be independent of the length of follow-up. Consistently with these results, meta-regression analysis showed a significant effect of the length of follow-up on FPG, but not on FPI, with the greatest reduction in FPG observed in the shortest follow-up. A possible explanation could be the onset of other metabolic risk factors in the longer follow-up, such as older age, familial predisposition, and the presence of other comorbidities, which could worsen the glycaemic status. This has been corroborated by the study from Colao in which patients gained weight during the long follow-up and deterioration of glucose tolerance was correlated with increased BMI and not with use of SSAs or surgery or disease control (22). Moreover, in the months immediately following neurosurgery, patients are probably followed more closely, improving their adherence to diet and treatment, and this can lead to 
better glycaemic control. Therefore, many confounding factors can potentially affect glucose homeostasis at short- and long-term after surgery. The subgroup analysis for disease control suggests that the improvement in FPG is dependent on disease remission. However, metaregression analysis showed that neither IGF1 nor GH MD affected the FPG MD. This discrepancy could be explained with the high heterogeneity of the cure criteria in the different studies, sometimes not acceptable as criteria for disease control today. In this respect, the results of metaregression, which are based on IGF1 and GH levels, are more reliable.

A large retrospective study documented a significant improvement in glucose homeostasis and insulin sensitivity after neurosurgery, not correlated with the achievement of biochemical control (47). Furthermore, a more recent paper demonstrated a significant improvement in glucose metabolism after neurosurgery in both cured and uncured patients (23). The authors affirmed that the improvement of acromegaly by neurosurgery, despite the lack of total cure, is assumed to have a positive influence on glucose homeostasis (23). It is possible to speculate that adenoma debulking and the consequent drop in IGF1 and GH levels could be responsible for the improved glucose metabolism, independently of disease control. Neurosurgery could thus improve the complications of acromegaly even when it is not curative.

There is a growing interest in the cost-effectiveness for acromegaly treatments (48). Some authors claim that curative surgery as a primary treatment has the lowest lifelong costs $(49,50,51,52)$. The potential reduction/ withdrawal of antidiabetic drugs after neurosurgery could improve its cost-benefit ratio, even when not curative, but it requires further studies.

To our knowledge, this is the first meta-analysis evaluating the effects of neurosurgery on metabolism in acromegaly aiming to establish if metabolic complications are reversible after neurosurgery and whether its effects are associated with disease control or length of follow-up. Our findings could help to fill one aspect, that of metabolictreatment-alignment, in the growing need for a tailored treatment of acromegaly based on the patients' clinical situation (53). However, it does have some limitations. The first was the high heterogeneity of the studies, although this is partially explained by subgroup analyses and metaregression. Secondly, it suffers from publication bias, as negative results are not always reported. Thirdly, most of the studies included both cured and uncured patients and it was not possible to separate them. Moreover, five studies only included data for cured patients, thus overestimating neurosurgery effect, since patients with a worse metabolic profile were probably excluded for active disease. Fourthly, the subgroup analysis for disease control was limited by the heterogeneous cure criteria used, so we cannot exclude that disease control does not play a role in the improvement of glucose homeostasis after neurosurgery. Fifth, in two studies the patients were pre-treated with SSAs and this may have influenced the results of the meta-analysis. Sixth, meta-regression was only possible for FPG and FPI, because of the paucity of studies providing data on the other outcomes. Finally, some studies not primarily intended to evaluate glucose homeostasis, which could be a source of bias.

\section{Conclusions}

This meta-analysis reveals that neurosurgery has a good impact on metabolism in acromegaly that seems to be influenced more by the length of follow-up than by disease control, with better results in the short-term than in the long-term. Metabolic parameters, which improve in the first months after neurosurgery, could later worsen due to other risk factors, including genetic background, lifestyle, and $\beta$-cell function at diagnosis.

These results thus reinforce the concept that neurosurgery could be considered a viable option to improve the metabolic complications of acromegaly, even when it cannot be curative. Our study also clearly indicates that the metabolic parameters as well as GH and IGF1 levels should be closely followed in the long-term, even in the cured patient, to enable prompt optimization of diabetes medications and hence reduce the cardiovascular morbidity and mortality.

\section{Supplementary materials}

This is linked to the online version of the paper at https://doi.org/10.1530/ EJE-20-0497.

\section{Declaration of interest}

A L reports personal fees from Merck Sharp \& Dohme, Novartis, Shire, Novo Nordisk, and Aegerion Pharmaceuticals. A M I reports grants and personal fees from Shire-Takeda, Sandoz, Novartis, and Ipsen. Andrea M Isidori is on the editorial board of EJE. Andrea M Isidori was not involved in the review or editorial process for this paper, on which he is listed as an author. The remaining authors have nothing to disclose.

\section{Funding}

This study was supported by the Ministry of Education, University and Research- Research Project of Relevant National Interest (PRIN) Grant 2017N8CK4K. 


\section{References}

1 Colao A, Ferone D, Marzullo P \& Lombardi G. Systemic complications of acromegaly: epidemiology, pathogenesis, and management. Endocrine Reviews 200425 102-152. (https://doi. org/10.1210/er.2002-0022)

2 Dekkers OM, Biermasz NR, Pereira AM, Romijn JA \& Vandenbroucke JP. Mortality in acromegaly: a metaanalysis. Journal of Clinical Endocrinology and Metabolism 200893 61-67. (https://doi. org/10.1210/jc.2007-1191)

3 Melmed S. Medical progress: acromegaly. New England Journal of Medicine 2006355 2558-2573. (https://doi.org/10.1056/ NEJMra062453)

4 Pivonello R, Auriemma RS, Grasso LF, Pivonello C, Simeoli C, Patalano R, Galdiero M \& Colao A. Complications of acromegaly: cardiovascular, respiratory and metabolic comorbidities. Pituitary 201720 46-62. (https://doi.org/10.1007/s11102-017-0797-7)

5 Frara S, Maffezzoni F, Mazziotti G \& Giustina A. Current and emerging aspects of diabetes mellitus in acromegaly. Trends in Endocrinology and Metabolism 201627 470-483. (https://doi. org/10.1016/j.tem.2016.04.014)

6 Kasayama S, Otsuki M, Takagi M, Saito H, Sumitani S, Kouhara H, Koga M, Saitoh Y, Ohnishi T \& Arita N. Impaired beta-cell function in the presence of reduced insulin sensitivity determines glucose tolerance status in acromegalic patients. Clinical Endocrinology 2000 52 549-555. (https://doi.org/10.1046/j.1365-2265.2000.00986.x)

7 Niculescu DA, Dusceac R, Caragheorgheopol A, Popescu N \& Poiana C. Disposition index in active acromegaly. Frontiers in Endocrinology 201910 637. (https://doi.org/10.3389/ fendo.2019.00637)

8 Wang Z, Gao L, Guo X, Feng C, Deng K, Lian W, Feng M, Bao X \& Xing B. Preoperative fasting C-peptide acts as a promising predictor of improved glucose tolerance in patients with acromegaly after transsphenoidal surgery: a retrospective study of 64 cases from a large pituitary center in China. Frontiers in Endocrinology $2019 \mathbf{1 0}$ 736. (https://doi.org/10.3389/fendo.2019.00736)

9 Olarescu NC \& Bollerslev J. The impact of adipose tissue on insulin resistance in acromegaly. Trends in Endocrinology and Metabolism 2016 27 226-237. (https://doi.org/10.1016/j.tem.2016.02.005)

10 Giustina A, Barkan A, Beckers A, Biermasz N, Biller BMK, Boguszewski C, Bolanowski M, Bonert V, Bronstein MD, Casanueva FF et al. A consensus on the diagnosis and treatment of acromegaly comorbidities: an update. Journal of Clinical Endocrinology and Metabolism 2020105 dgz096. (https://doi.org/10.1210/clinem/ dgz096)

11 Katznelson L, Laws Jr ER, Melmed S, Molitch ME, Murad MH, Utz A, Wass JA \& Endocrine Society. Acromegaly: an endocrine society clinical practice guideline. Journal of Clinical Endocrinology and Metabolism 201499 3933-3951. (https://doi.org/10.1210/jc.20142700)

12 Bollerslev J, Heck A \& Olarescu NC. MANAGEMENT OF ENDOCRINE DISEASE: Individualised management of acromegaly. European Journal of Endocrinology 2019181 R57-R71. (https://doi.org/10.1530/ EJE-19-0124)

13 Ferrau F, Albani A, Ciresi A, Giordano C \& Cannavo S. Diabetes secondary to acromegaly: physiopathology, clinical features and effects of treatment. Frontiers in Endocrinology 20189 358. (https:// doi.org/10.3389/fendo.2018.00358)

14 Kinoshita Y, Fujii H, Takeshita A, Taguchi M, Miyakawa M, Oyama K, Yamada S \& Takeuchi Y. Impaired glucose metabolism in Japanese patients with acromegaly is restored after successful pituitary surgery if pancreatic \{beta\}-cell function is preserved. European Journal of Endocrinology 2011164 467-473. (https://doi.org/10.1530/EJE-101096)

15 Moher D, Liberati A, Tetzlaff J, Altman DG \& PRISMA Group. Preferred reporting items for systematic reviews and meta-analyses: the PRISMA statement. Journal of Clinical Epidemiology 200962 1006-1012. (https://doi.org/10.1016/j.jclinepi.2009.06.005)

16 Liberati A, Altman DG, Tetzlaff J, Mulrow C, Gotzsche PC, Ioannidis JP, Clarke M, Devereaux PJ, Kleijnen J \& Moher D. The PRISMA statement for reporting systematic reviews and meta-analyses of studies that evaluate health care interventions: explanation and elaboration. Journal of Clinical Epidemiology 200962 e1-34. (https://doi.org/10.1016/j.jclinepi.2009.06.006)

17 Landin K, Petruson B, Jakobsson KE \& Bengtsson BA. Skeletal muscle sodium and potassium changes after successful surgery in acromegaly: relation to body composition, blood glucose, plasma insulin and blood pressure. Acta Endocrinologica 1993128 418-422. (https://doi.org/10.1530/acta.0.1280418)

18 Moller N, Schmitz O, Joorgensen JO, Astrup J, Bak JF, Christensen SE, Alberti KG \& Weeke J. Basal- and insulin-stimulated substrate metabolism in patients with active acromegaly before and after adenomectomy. Journal of Clinical Endocrinology and Metabolism 1992 74 1012-1019. (https://doi.org/10.1210/jcem.74.5.1569148)

19 Higgins JP, Altman DG, Gotzsche PC, Juni P, Moher D, Oxman AD, Savovic J, Schulz KF, Weeks L, Sterne JA et al. The Cochrane Collaboration's tool for assessing risk of bias in randomised trials. BMJ 2011343 d5928. (https://doi.org/10.1136/bmj.d5928)

20 Hozo SP, Djulbegovic B \& Hozo I. Estimating the mean and variance from the median, range, and the size of a sample. BMC Medical Research Methodology 20055 13. (https://doi.org/10.1186/1471-22885-13)

21 Higgins JP, Thompson SG, Deeks JJ \& Altman DG. Measuring inconsistency in meta-analyses. BMJ 2003327 557-560. (https://doi. org/10.1136/bmj.327.7414.557)

22 Colao A, Auriemma RS, Galdiero M, Cappabianca P, Cavallo LM, Esposito F, Grasso LF, Lombardi G \& Pivonello R. Impact of somatostatin analogs versus surgery on glucose metabolism in acromegaly: results of a 5-year observational, open, prospective study. Journal of Clinical Endocrinology and Metabolism 200994 528-537. (https://doi.org/10.1210/jc.2008-1546)

23 Helseth R, Carlsen SM, Bollerslev J, Svartberg J, Oksnes M, Skeie S $\&$ Fougner SL. Preoperative octreotide therapy and surgery in acromegaly: associations between glucose homeostasis and treatment response. Endocrine 201651 298-307. (https://doi.org/10.1007/ s12020-015-0679-6)

24 Winhofer Y, Wolf P, Krssak M, Wolfsberger S, Tura A, Pacini G, Gessl A, Raber W, Kukurova IJ, Kautzky-Willer A et al. No evidence of ectopic lipid accumulation in the pathophysiology of the acromegalic cardiomyopathy. Journal of Clinical Endocrinology and Metabolism 201499 4299-4306. (https://doi.org/10.1210/jc.20142242)

25 Damjanovic SS, Petakov MS, Raicevic S, Micic D, Marinkovic J, Dieguez C, Casanueva FF \& Popovic V. Serum leptin levels in patients with acromegaly before and after correction of hypersomatotropism by trans-sphenoidal surgery. Journal of Clinical Endocrinology and Metabolism 200085 147-154. (https://doi.org/10.1210/ jcem.85.1.6296)

26 Freda PU, Reyes CM, Conwell IM, Sundeen RE \& Wardlaw SL. Serum ghrelin levels in acromegaly: effects of surgical and longacting octreotide therapy. Journal of Clinical Endocrinology and Metabolism 200388 2037-2044. (https://doi.org/10.1210/jc.2002021683)

27 Hoybye C, Chandramouli V, Efendic S, Hulting AL, Landau BR, Schumann WC \& Wajngot A. Contribution of gluconeogenesis and glycogenolysis to hepatic glucose production in acromegaly before and after pituitary microsurgery. Hormone and Metabolic Research 200840 498-501. (https://doi.org/10.1055/s-2008-1065322)

28 Mori K, Iwasaki Y, Kawasaki-Ogita Y, Honjo S, Hamamoto Y, Tatsuoka H, Fujimoto K, Ikeda H, Wada Y, Takahashi Y et al. Improvement of insulin resistance following transsphenoidal surgery in patients with acromegaly: correlation with serum IGF-I levels. 
Journal of Endocrinological Investigation 201336 853-859. (https://doi. org/10.3275/8964)

29 Reyes-Vidal C, Fernandez JC, Bruce JN, Crisman C, Conwell IM, Kostadinov J, Geer EB, Post KD \& Freda PU. Prospective study of surgical treatment of acromegaly: effects on ghrelin, weight, adiposity, and markers of CV risk. Journal of Clinical Endocrinology and Metabolism 201499 4124-4132. (https://doi.org/10.1210/jc.20142259)

30 Reyes-Vidal CM, Mojahed H, Shen W, Jin Z, Arias-Mendoza F, Fernandez JC, Gallagher D, Bruce JN, Post KD \& Freda PU. Adipose tissue redistribution and ectopic lipid deposition in active acromegaly and effects of surgical treatment. Journal of Clinical Endocrinology and Metabolism 2015100 2946-2955. (https://doi. org/10.1210/jc.2015-1917)

31 Oscarsson J, Wiklund O, Jakobsson KE, Petruson B \& Bengtsson BA. Serum lipoproteins in acromegaly before and 6-15 months after transsphenoidal adenomectomy. Clinical Endocrinology $1994 \mathbf{4 1}$ 603-608. (https://doi.org/10.1111/j.1365-2265.1994.tb01825.x)

32 Wasada T, Aoki K, Sato A, Katsumori K, Muto K, Tomonaga O, Yokoyama H, Iwasaki N, Babazono T, Takahashi C et al. Assessment of insulin resistance in acromegaly associated with diabetes mellitus before and after transsphenoidal adenomectomy. Endocrine Journal 199744 617-620. (https://doi.org/10.1507/endocrj.44.617)

33 Sakai H, Tsuchiya K, Nakayama C, Iwashima F, Izumiyama H, Doi M, Yoshimoto T, Tsujino M, Yamada S \& Hirata Y. Improvement of endothelial dysfunction in acromegaly after transsphenoidal surgery. Endocrine Journal 200855 853-859. (https://doi.org/10.1507/endocrj. k07e-125)

34 Sze L, Bernays RL, Zwimpfer C, Wiesli P, Brandle M \& Schmid C. Excessively high soluble klotho in patients with acromegaly. Journal of Internal Medicine 2012272 93-97. (https://doi.org/10.1111/j.13652796.2012.02542.x)

35 Wiesli P, Bernays R, Brandle M, Zwimpfer C, Seiler H, Zapf J, A Spinas G \& Schmid C. Effect of pituitary surgery in patients with acromegaly on adiponectin serum concentrations and alanine aminotransferase activity. Clinica Chimica Acta: International Journal of Clinical Chemistry 2005352 175-181. (https://doi.org/10.1016/j. cccn.2004.09.022)

36 Jaffrain-Rea ML, Minniti G, Moroni C, Esposito V, Ferretti E, Santoro A, Infusino T, Tamburrano G, Cantore G \& Cassone R. Impact of successful transsphenoidal surgery on cardiovascular risk factors in acromegaly. European Journal of Endocrinology 2003148 193-201. (https://doi.org/10.1530/eje.0.1480193)

37 Akutsu H, Kreutzer J, Wasmeier G, Ropers D, Rost C, Mohlig M, Wallaschofski H, Buchfelder M \& Schofl C. Acromegaly per se does not increase the risk for coronary artery disease. European Journal of Endocrinology 2010162 879-886. (https://doi.org/10.1530/EJE-090945)

38 Battezzati A, Benedini S, Fattorini A, Losa M, Mortini P, Bertoli S, Lanzi R, Testolin G, Biolo G \& Luzi L. Insulin action on protein metabolism in acromegalic patients. American Journal of Physiology: Endocrinology and Metabolism 2003284 E823-E829. (https://doi. org/10.1152/ajpendo.00020.2002)

39 Holdaway IM, Rajasoorya RC \& Gamble GD. Factors influencing mortality in acromegaly. Journal of Clinical Endocrinology and Metabolism 200489 667-674. (https://doi.org/10.1210/jc.2003031199)

40 Gonzalez B, Vargas G, de Los Monteros ALE, Mendoza V \& Mercado M. Persistence of diabetes and hypertension after multimodal treatment of acromegaly. Journal of Clinical Endocrinology and Metabolism 2018103 2369-2375. (https://doi.org/10.1210/ jc.2018-00325)

41 Cozzolino A, Feola T, Simonelli I, Puliani G, Pozza C, Giannetta E, Gianfrilli D, Pasqualetti P, Lenzi A \& Isidori AM. Somatostatin analogs and glucose metabolism in acromegaly: a meta-analysis of prospective interventional studies. Journal of Clinical Endocrinology and Metabolism 2018103 2089-2099. (https://doi.org/10.1210/jc.2017-02566)

42 Feola T, Cozzolino A, Simonelli I, Sbardella E, Pozza C, Giannetta E, Gianfrilli D, Pasqualetti P, Lenzi A \& Isidori AM. Pegvisomant improves glucose metabolism in acromegaly: a meta-analysis of prospective interventional studies. Journal of Clinical Endocrinology and Metabolism 2019104 2892-2902. (https://doi.org/10.1210/ jc.2018-02281)

43 Jonas C, Maiter D \& Alexopoulou O. Evolution of glucose tolerance after treatment of acromegaly: a study in 57 patients. Hormone and Metabolic Research 201648 299-305. (https://doi. org/10.1055/s-0035-1569277)

44 Rochette C, Graillon T, Albarel F, Morange I, Dufour H, Brue T $\&$ Castinetti F. Increased risk of persistent glucose disorders after control of acromegaly. Journal of the Endocrine Society 20171 1531-1539. (https://doi.org/10.1210/js.2017-00334)

45 Fieffe S, Morange I, Petrossians P, Chanson P, Rohmer V, Cortet C, Borson-Chazot F, Brue T, Delemer B \& French Acromegaly Registry. Diabetes in acromegaly, prevalence, risk factors, and evolution: data from the French Acromegaly Registry. European Journal of Endocrinology 2011164 877-884. (https://doi.org/10.1530/EJE-101050)

46 Alexopoulou O, Bex M, Kamenicky P, Mvoula AB, Chanson P \& Maiter D. Prevalence and risk factors of impaired glucose tolerance and diabetes mellitus at diagnosis of acromegaly: a study in 148 patients. Pituitary 201417 81-89. (https://doi.org/10.1007/s11102013-0471-7)

47 Stelmachowska-Banas M, Zielinski G, Zdunowski P, Podgorski J \& Zgliczynski $W$. The impact of transsphenoidal surgery on glucose homeostasis and insulin resistance in acromegaly. Neurologia $i$ Neurochirurgia Polska 201145 328-334. (https://doi.org/10.1016/ s0028-3843(14)60103-1)

48 Lesen E, Granfeldt D, Houchard A, Dinet J, Berthon A, Olsson DS, Bjorholt I \& Johannsson G. Comorbidities, treatment patterns and cost-of-illness of acromegaly in Sweden: a register-linkage population-based study. European Journal of Endocrinology 2017176 203-212. (https://doi.org/10.1530/EJE-16-0623)

49 Biermasz NR, Roelfsema F, Pereira AM \& Romijn JA. Costeffectiveness of lanreotide Autogel in treatment algorithms of acromegaly. Expert Review of Pharmacoeconomics and Outcomes Research 20099 223-234. (https://doi.org/10.1586/erp.09.17)

50 Kimmell KT, Weil RJ \& Marko NF. Multi-modal management of acromegaly: a value perspective. Pituitary 201518 658-665. (https:// doi.org/10.1007/s11102-014-0626-1)

51 Leonart LP, Borba HHL, Ferreira VL, Riveros BS \& Pontarolo R. Costeffectiveness of acromegaly treatments: a systematic review. Pituitary 201821 642-652. (https://doi.org/10.1007/s11102-018-0908-0)

52 Marko NF, LaSota E, Hamrahian AH \& Weil RJ. Comparative effectiveness review of treatment options for pituitary microadenomas in acromegaly. Journal of Neurosurgery 2012117 522-538. (https://doi.org/10.3171/2012.4.JNS11739)

53 Kasuki L, Wildemberg LE \& Gadelha MR. MANAGEMENT OF ENDOCRINE DISEASE: Personalized medicine in the treatment of acromegaly. European Journal of Endocrinology 2018178 R89-R100. (https://doi.org/10.1530/EJE-17-1006)

Received 9 May 2020

Revised version received 4 September 2020

Accepted 17 September 2020 